\title{
A Sensor for Detection of 4-nitrophenol Based on a Glassy Carbon Electrode Modified with a Reduced Graphene Oxide $/ \mathrm{Fe}_{3} \mathrm{O}_{4}$ Nanoparticle Composite
}

\author{
Yongqiang Cheng, Yaohua Li, Dan Li, Bo Zhang, Runfang Hao, and Shengbo Sang* \\ MicroNano System Research Center, Key Lab of Advanced Transducers and Intelligent Control \\ System of the Ministry of Education \& College of Information Engineering, Taiyuan University of \\ Technology, Taiyuan 030024, China \\ *E-mail: sangshengbo@tyut.edu.cn
}

doi: $10.20964 / 2017.08 .08$

Received: 12 April 2017 / Accepted: 25 May 2017 / Published: 12 July 2017

A simple sensor, based on a glassy carbon electrode (GCE) modified with a reduced graphene oxide (RGO) and $\mathrm{Fe}_{3} \mathrm{O}_{4}$ nanoparticle composites $\left(\mathrm{Fe}_{3} \mathrm{O}_{4} \mathrm{NPs}\right)$, was developed for detection of 4-nitrophenol (4-NP). The surface morphology of the prepared reduced graphene oxide/ $/ \mathrm{Fe}_{3} \mathrm{O}_{4}$ nanoparticle composites was characterized by scanning electron microscopy (SEM). The RGO/ $\mathrm{Fe}_{3} \mathrm{O}_{4} \mathrm{NPs}$ modified GCE was confirmed by cyclic voltammogram (CV) and electrochemical impedance spectroscopy (EIS). The electrochemical behaviors of the as-obtained $\mathrm{RGO} / \mathrm{Fe}_{3} \mathrm{O}_{4} \mathrm{NPs}$ toward 4-NP were investigated with differential pulse voltammetry (DPV) and square wave voltammetry (SWV). Under the optimal experimental conditions, the linear relationship between the peak current and the concentration of 4-NP was obtained from DPV in the range from 0.2 to $10 \mu \mathrm{M}, 20$ to $100 \mu \mathrm{M}$ and SWV in the range from 0.2 to $10 \mu \mathrm{M}$. And respectively, the limit of detection (LOD) of 4-NP was 0.26 $\mu \mathrm{M}$ and $0.86 \mu \mathrm{M}$ for DPV and SWV. The sensor was used to determine the level of 4-NP in tap water samples with good recovery, highlighting the sensor's feasibility for industrial applications. The proposed sensor provided an efficient performances and acceptable stability for the detection of 4-NP in the water.

Keywords: DPV, electrochemical detection, $\mathrm{Fe}_{3} \mathrm{O}_{4}, \mathrm{RGO}, 4-\mathrm{NP}$

\section{$\underline{\text { FULL TEXT }}$}

(C) 2017 The Authors. Published by ESG (www.electrochemsci.org). This article is an open access article distributed under the terms and conditions of the Creative Commons Attribution license (http://creativecommons.org/licenses/by/4.0/). 